\title{
A population-based study on the risk of cervical cancer and cervical intraepithelial neoplasia among grand multiparous women in Finland
}

\author{
M Hinkula*,', E Pukkala ${ }^{2}$, P Kyyrönen², P Laukkanen ${ }^{2,3}$, P Koskela ${ }^{3}$, J Paavonen ${ }^{4}$, M Lehtinen ${ }^{5}$ and A Kauppila' \\ 'Department of Obstetrics and Gynecology, University of Oulu, PL 24, FIN-90029 OYS, Finland; ' ${ }^{2}$ innish Cancer Registry, Institute for Statistical and \\ Epidemiological Cancer Research, Helsinki, Finland; ${ }^{3}$ National Public Health Institute, Oulu, Finland; ${ }^{4}$ Department of Obstetrics and Gynecology, University \\ of Helsinki, Finland; ${ }^{5}$ National Public Health Institute, Helsinki, Finland
}

\begin{abstract}
Previous studies suggest that high parity increases the risk of cervical cancer. We studied the risk of cervical cancer (CC) and cervical intraepithelial neoplasia (CIN3) in a Finnish cohort of grand multiparous (GM) women (at least five children) with low prevalence of sexually transmitted infections (STI). The Finnish Cancer Registry data revealed 220 CC and 178 CIN3 cases among 86978 GM women. Standardised incidence ratios (SIR) were calculated from the numbers of observed and expected cases. Interval analyses by parity, age at first birth and average birth interval were done using multivariate Poisson regression. Seroprevalence of human papillomavirus (HPV) 16 and Chlamydia trachomatis was tested among 56 I GM women and 5703 women with 2-4 pregnancies. The incidence among GM women was slightly above the national average for squamous cell carcinoma of cervix uteri (SIR I.21, 95\% CI I.05-1.40) and CIN3 (1.37, 95\% Cl I. I 7- I.58), but lower for adenocarcinoma (SIR 0.77, 95\% Cl 0.52- I. I0). The seroprevalence of HPV 6 and Chlamydia trachomatis among GM women was lower than in the reference population, except among those women who had their child under age 19. Age under 20 years at first birth increased the risk of CC and CIN3 especially in premenopausal GM women, while increasing parity had no effect. The small relative risks of CC and CIN3 among GM women in our study as compared to studies from other countries can be explained by the exceptionally low prevalence of STIs in Finnish GM women. The observed SIRs between 1.2 and I.4 should be interpreted to represent increased risk attributable to grand multiparity. The increased incidence of CC and CIN3 among young GM women suggests causal association to HPV 16 and Chlamydia trachomatis infections. British Journal of Cancer (2004) 90, 1025-1029. doi:I0.1038/sj.bjc.660I650 www.bjcancer.com (c) 2004 Cancer Research UK
\end{abstract}

Keywords: cervical cancer; cervical intraepithelial neoplasia; risk factors; parity; human papillomavirus; Chlamydia trachomatis

Multiparity is believed to be a risk factor for cervical cancer (CC), especially among human papilloma virus (HPV)-positive women (Eluf-Neto et al, 1994). The relative risk (RR) of CC among women with five or more births varied from 3.8 (in squamous cell carcinoma) (Munoz et al, 2002) to 4.4 (Parazzini et al, 1989) in recent studies, compared with nulliparous, or 5.1 compared with nulliparous or primiparous women (Brinton et al, 1989).

Human papillomavirus, most notably types HPV16 and 18 (Munoz et al, 1994; Lehtinen et al, 1996; Dillner et al, 1997; Walboomers et al, 1999; Wallin et al, 1999) and Chlamydia trachomatis infections (Koskela et al, 2000; Anttila et al, 2001) have an important role in the aetiology of CC. Postulated risk factors for CC include, for example, use of oral contraceptives and smoking (La Vecchia et al, 1986; Brinton et al, 1987b; Schiffman and Brinton, 1995; Schiffman et al, 1996; Hakama et al, 2000).

We studied the significance of multiparity in the aetiology of cervical cancer of Finnish grand multiparous (GM) women with at least five biological children (Solomons, 1934). Most of the GM

*Correspondence: Dr M Hinkula; E-mail: marianne.hinkula@oulu.fi Received 10 October 2003; revised 12 December 2003; accepted 15 December 2003 women belong to the religious movement of Laestadius within the Lutheran church. High parity is common within this movement, as any kind of contraception is forbidden. Other life habits of the members in this group do not markedly differ from the ordinary Finns. Smoking is permitted, but alcohol consumption is unusual. Since extramarital sexual contacts are unacceptable and rare in this movement, the risk of HPV and Chlamydia trachomatis infections of Finnish GM women is presumably low.

\section{MATERIAL AND METHODS}

The computerised files of the Finnish Population Register revealed 86978 women with at least five children until the end of 1997 . The files include links between parents and their children living at the same address in 1974 or later. Follow-up for CC and CIN was done automatically through the files of the national population-based Finnish Cancer Registry with personal identifiers as the key. The cancer registry data also included information about clinical stage and histopathological diagnosis. The CIN group includes patients with histological diagnosis of carcinoma in situ or severe dysplasia in the old classification, or CIN grade 3 in the new classification. 
The Finnish Maternity Cohort (FMC) of the National Public Health Institute has collected and stored (at $-25^{\circ} \mathrm{C}$ ) first trimester serum samples from all (98\%) pregnant women in Finland since 1983. Seroprevalences of HPV16 and Chlamydia trachomatis were analysed in a stratified random sample of 6264 women with two pregnancies in FMC with standard ELISA methods (Laukkanen et al, 2003). These women were linked with the GM cohort. The FMC comprised 561 GM women, whose HPV16 and Chlamydia trachomatis seroprevalence was compared with that of women of the same age and period in the rest of sample $(n=5703)$.

\section{STATISTICAL METHODS}

The follow-up started from the birth of the fifth child or first of January 1974, whichever was later and ended at emigration, death or 31 of December 1997, whichever overcame first. The number of person years was 1.68 million.

The numbers of observed cases of CC and CIN3 and personyears at risk were counted by 5 -year age groups and separately for four parity categories $(5,6,7$ and $8+$ children), four categories by the age at first birth $(<20,20-24,25-29$ and $30+$ years $)$ and three birth interval categories according to the average interval between the first five deliveries $(<2.0,2.0-3.0$ and $>3.0$ years). Age at follow-up of cancer was categorised into four groups $(<40$, $40-49,50-64$ and $65+$ years).

The expected numbers of cases were calculated by multiplying the number of person-years in each stratum by the corresponding incidence rate in Finland. The standardised incidence ratio (SIR) was calculated by dividing the number of observed cases by the number of expected cases. The $95 \%$ confidence intervals ( $95 \%$ CI) for the SIRs were based on the assumption that the number of observed cases presents a Poisson distribution.

Poisson regression modelling of the stratum-specific observed and expected number was used to assess the effects (RR) of all relevant variables simultaneously. The analyses were performed using the SAS statistical software (1997).

\section{RESULTS}

GM women had $220 \mathrm{CC}$ and $178 \mathrm{CIN} 3$ cases, only slightly more than expected (CC; SIR 1.13, 95\% CI 0.98-1.29) (CIN3; SIR 1.37, 95\% CI 1.17-1.58). The SIR of both CC and CIN3 was smallest among women with at least eight children (Table 1). The younger the age at first birth, the greater was the SIR of CC and CIN3. The SIR of CIN3 was significantly above the national average in women with the average birth interval under 3 years. The excess in incidence of CC was only seen in cancer diagnosed in women under 50 years of age (SIR 1.56, 95\% CI 1.18-2.02), 26\% of cases.

In all, 190 cases had squamous-cell carcinoma (SCC) (86\%) and 30 cases had adenocarsinoma (14\%). The incidence of SCC was above (SIR 1.21, 95\% CI 1.05-1.40) and that of adenocarcinoma slightly below (SIR $0.77,95 \%$ CI $0.52-1.10$ ) the national average. Increasing parity and long birth interval seemed to decrease the SIR of adenocarsinoma (SIR for $8+$ birth, 0.22 and 95\% CI $0.01-$ 1.20; SIR for birth interval > 3.0 year, 0.41 and $95 \%$ CI $0.13-0.95$ ), but the number of cases was small for proper evaluations.

The disease represented clinical (according to Finnish Cancer registry) stage I in $57 \%$, stage II in $11 \%$ and stage III in $32 \%$ of the 195 cases with a known stage. The Stage II cases had increased SIR (SIR 1.74, 95\% CI 1.09-2.64), but in other stages SIRs were about the same as SIR for CC (Stage I, SIR 1.17 and 95\% CI $0.97-1.41$; Stage III, SIR 1.08 and 95\% CI $0.83-1.39$ ).

According to multivariate analysis, the RR for CC in ages under 40 years was 2.30 -fold ( $95 \%$ CI $1.27-4.16$ ) compared with cases above 65 years of age, if the reproductive factors were the same (Table 2). Young age at first birth was associated with increased risk of both CC and CIN3. This phenomenon in CC (Table 3) or CIN3 (Table 3) was, however, significant only among GM women under 50 years of age. In postmenopausal GM women, an increased CIN3 risk was associated with short birth interval (Table 3).

The seroprevalence of HPV16 and Chlamydia trachomatis among the $561 \mathrm{GM}$ women included into the FMC sample of 6264 women were 10 and $11 \%$, respectively, which was about half of that in the rest of the sample (Figure 1). GM women under 19

Table I Observed (Obs) and expected (Exp) number of cervical intraepithelial neoplasia (CIN3) and cervical cancer (CC) cases and standardised incidence ratios $(\mathrm{SIR}=\mathrm{Obs} / \mathrm{Exp})$, with $95 \%$ confidence intervals $(95 \% \mathrm{Cl})$, among women with at least five children

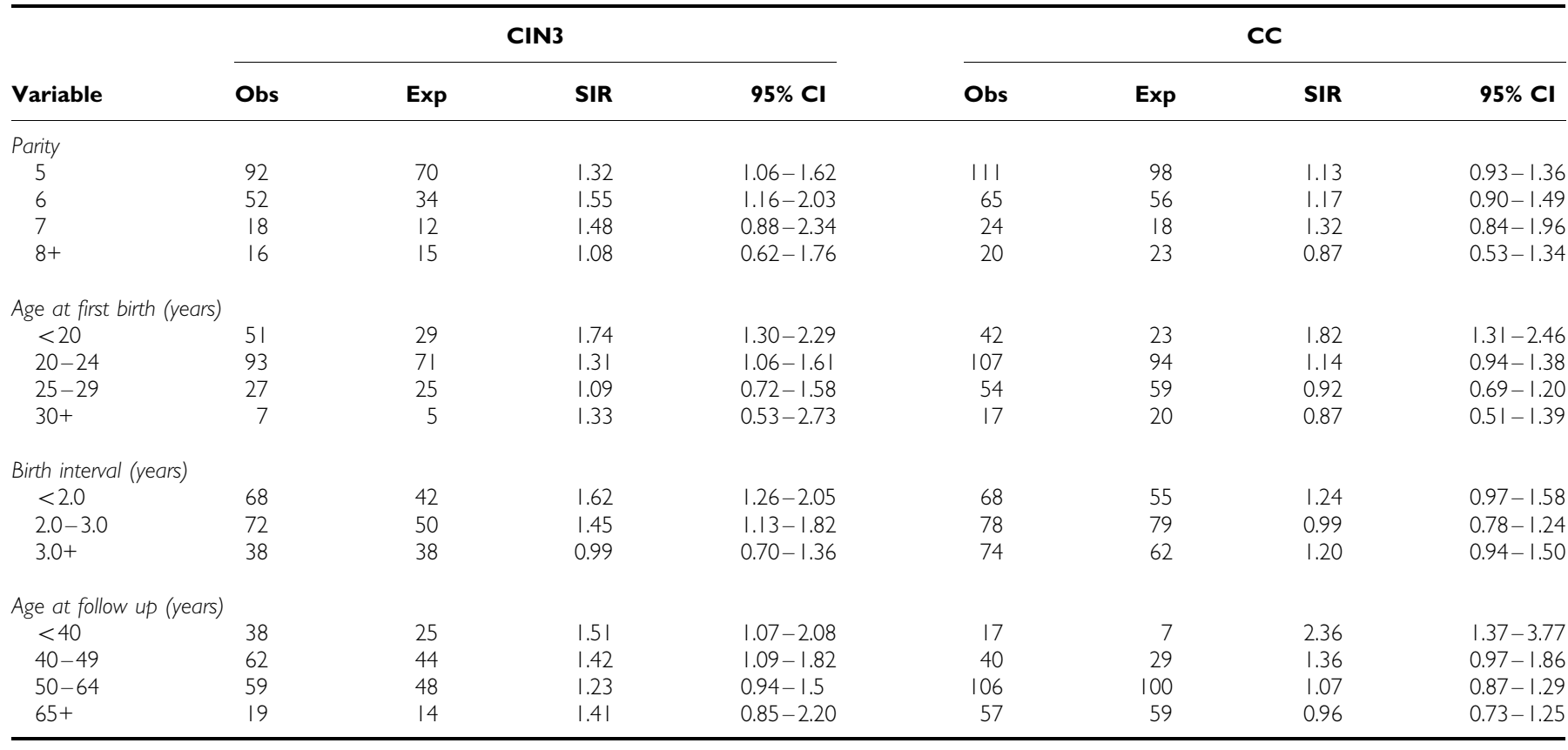


years of age had during the pregnancy high HPV16 and Chlamydia trachomatis seroprevalences (27\% and $16 \%)$.

\section{DISCUSSION}

We studied the widely accepted hypothesis that multiparity is associated with increased risk for CC and CIN in a national cohort of GM women in Finland. The national population-based databanks of the Finnish Population Register and the Finnish

Table 2 Relative risks (RR) with 95\% confidence intervals (95\% Cl) for cervical intraepithelial neoplasia (CIN3) and cervical cancer (CC) among women with at least five children, by study variables, adjusted for each other

\begin{tabular}{|c|c|c|c|c|}
\hline \multirow[b]{2}{*}{ Variable } & \multicolumn{2}{|c|}{ CIN3 } & \multicolumn{2}{|c|}{ CC } \\
\hline & $\mathbf{R R}$ & $95 \% \mathrm{Cl}$ & $\mathbf{R R}$ & $95 \% \mathrm{Cl}$ \\
\hline \multicolumn{5}{|l|}{ Parity } \\
\hline 5 & 1.00 & Ref & 1.00 & Ref \\
\hline 6 & 1.03 & $0.72-1.47$ & 1.08 & $0.78-1.48$ \\
\hline 7 & 0.90 & $0.54-1.53$ & 1.14 & $0.72-1.82$ \\
\hline $8+$ & 0.63 & $0.36-1.11$ & 0.73 & $0.44-1.21$ \\
\hline \multicolumn{5}{|c|}{ Age at first birth (years) } \\
\hline$<20$ & 1.00 & $\operatorname{Ref}^{\mathrm{a}}$ & 1.00 & Ref \\
\hline $20-24$ & 0.72 & $0.51-1.02$ & 0.73 & $0.51-1.06$ \\
\hline $25-29$ & 0.54 & $0.33-0.90$ & 0.66 & $0.42-1.03$ \\
\hline $30+$ & 0.57 & $0.24-1.33$ & 0.65 & $0.35-1.23$ \\
\hline \multicolumn{5}{|c|}{ Birth interval (years) } \\
\hline$<2.0$ & 1.00 & $\operatorname{Ref}^{b}$ & 1.00 & Ref \\
\hline $2.0-3.0$ & 0.81 & $0.58-1.15$ & 0.79 & $0.57-1.11$ \\
\hline $3.0+$ & 0.52 & $0.34-0.81$ & 0.91 & $0.63-1.33$ \\
\hline \multicolumn{5}{|c|}{ Age at follow up (years) } \\
\hline$<40$ & 0.73 & $0.39-1.37$ & 2.30 & $1.27-4.18^{c}$ \\
\hline $40-49$ & 0.74 & $0.40-1.37$ & 1.55 & $0.95-2.52$ \\
\hline $50-64$ & 0.74 & $0.42-1.29$ & 1.25 & $0.87-1.81$ \\
\hline $65+$ & 1.00 & Ref & 1.00 & Ref \\
\hline
\end{tabular}

${ }^{\mathrm{a}}$ Trend $P=0.02 .{ }^{\mathrm{b}}$ Trend $P=0.004 .{ }^{\mathrm{C}}$ Trend $P=0.0003$
Cancer Registry are virtually complete and the computerised record linkage using personal identifiers as a key is precise.

In this study, the incidence of CC and CIN3 among GM women was slightly higher than that among average female population. In Italy, the RR for $\mathrm{CC}$ for 5-paras was 4.4 compared with nulliparous women (Parazzini et al, 1989). In the Multicentric IARC study with low- and high-risk countries for 7-paras, the RR of SCC was 3.8 compared with nulliparas and 2.3 compared with women with one or two full-term pregnancies (Munoz et al, 2002). In the Latin American countries, the RR was 5.1 for $14+$-paras compared with

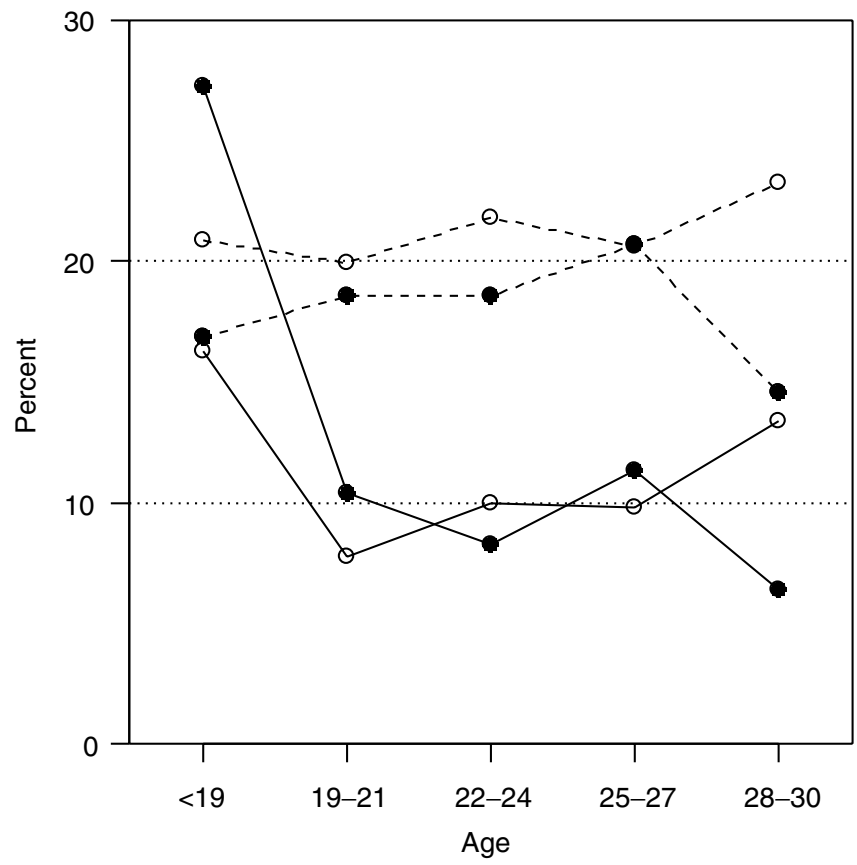

Figure I Prevalence of HPVI6 $(\bullet)$ and Chlamydia trachomatis $(O)$ among GM women (solid line, - ), and women with 2-4 pregnancies (dotted lines, -- ), in 1983-1993, by age at pregnancy.

Table 3 Observed number of cervical cancer (CC) cases (Obs) and cervical intraepithelial neoplasia (CIN3) and model-based relative risks (RR) according to study variables with 95\% confidence intervals (Cl 95\%) among GM women, by age at diagnosis

\begin{tabular}{|c|c|c|c|c|c|c|c|c|c|c|c|c|}
\hline Variable & \multicolumn{6}{|c|}{ CC } & \multicolumn{6}{|c|}{ CIN3 } \\
\hline \multicolumn{13}{|l|}{ Parity } \\
\hline 5 & 31 & 1.00 & Ref & 80 & 1.00 & Ref & 55 & 1.00 & Ref & 37 & 1.00 & Ref \\
\hline 6 & 11 & 0.76 & $0.37-1.53$ & 54 & 1.15 & $0.80-1.64$ & 24 & 0.97 & $0.59-1.59$ & 28 & 1.11 & $0.67-1.83$ \\
\hline \multicolumn{13}{|c|}{ Age at first birth (years) } \\
\hline$<20$ & 24 & 1.00 & $\operatorname{Ref}^{a}$ & 18 & 1.00 & Ref & 42 & 1.00 & $\operatorname{Ref}^{b}$ & 9 & 1.00 & Ref \\
\hline $20-24$ & 30 & 0.62 & $0.36-1.06$ & 77 & 0.78 & $0.46-1.30$ & 52 & 0.68 & $0.45-1.02$ & 41 & 1.01 & $0.49-2.08$ \\
\hline $25+$ & 3 & 0.25 & $0.07-0.83$ & 68 & 0.71 & $0.42-1.21$ & 6 & 0.35 & $0.15-0.83$ & 28 & 0.93 & $0.43-2.02$ \\
\hline \multicolumn{13}{|c|}{ Birth interval (years) } \\
\hline
\end{tabular}

${ }^{\mathrm{a}}$ Trend $P=0.01 .{ }^{\mathrm{b}}$ Trend $P=0.005 .{ }^{\mathrm{c}}$ Trend $P=0.005$. 
nulli- or primiparous women (Brinton et al, 1989). Italian women younger than 45 years with three or more births had an increased risk of 8.1 compared with nulliparous women, and the RR increased with the number of births (Parazzini et al, 1998). All these RR estimates are clearly higher than the RR of 1.13 seen in our study. In addition, GM women did not show any trend towards increasing risk of $\mathrm{CC}$ or $\mathrm{CIN} 3$, with rising number of births from 5 to $8+$. The risk estimate was actually lowest in women with $8+$ births. Anyway, as our reference group was the entire population with the mean number of 1.5-1.7 births per woman during the study period (www.stat.fi), the RR estimates might have been larger, when compared to nulliparous women.

There are also studies which do not show any role for multiparity in the aetiology of CC or CIN (Rotkin, 1973; Kvale et al, 1988; Cuzick et al, 1996). In those studies, crude RRs of CC were 0.6-2.3 for women with five or more pregnancies. However, after adjustment for the age at first birth the RR dropped close to 1.0. Similar RRs for CIN have been found in several studies adjusted for age at first birth or number of sexual partners (Parazzini et al, 1989, 1992; Jones et al, 1990).

The incidence of CC in Finland is low due to the nationwide organised Pap smear screening programmes, conducted since 1965 with 5-year interval among women over 30 years of age (Hakama, 1985). Maternal health care with several pelvic examinations during pregnancy and puerperium (including Pap smears) has been free of charge for over 40 years in Finland with $98 \%$ participation rate. These national programmes have promoted the early detection and treatment of CINs, and thus decreased CC incidence in Finnish women. It seems unlikely that these public health programmes have reduced the CC differently in GM women than in the rest of the population. The Pap smear screening and maternal health-care programmes are unlikely to bias our RR estimates. However, these programmes have changed the stage and histology distribution of CC in Finland. The fraction of slowgrowing cancers has strongly decreased. Screening also reduces mainly SCC, and therefore the relative proportion of adenocarcinoma increases (Anttila et al, 1999). The effect of parity is also dissimilar to different stages or histologies, and this can make it difficult to compare RRs observed in Finland and other countries.

Reproductive factors affect the pathogenesis of SCC and adenocarcinoma in different ways (Munoz et al, 2002). The incidence of cervical adenocarcinoma among Finnish GM women was low, a finding that resembles the results of our previous studies on adenocarcinoma of the breast (Hinkula et al, 2001) and endometrium (Hinkula et al, 2002). Cervical adenocarcinoma may resemble endometrial adenocarcinoma, as regards aetiological association with nulliparity and obesity (Schiffman et al, 1996). According to the study by Brinton et al (1993), the cervical adenocarcinoma appeared to be less affected by sexual and reproductive factors, whereas in study by Italian, the RR of adenocarcinoma increased with the number of births (Parazzini et al, 1988). The epidemiology of cervical adenocarcinoma is still poorly understood (Korhonen, 1980).

There are several pregnancy-induced cervical changes, which may predispose to malignant transformation. Multiparity may increase the risk of CC by maintaining the transformation zone on the ectocervical region. Moreover, the number of squamous metaplastic cells in the transformation zone increases during pregnancy (Munoz et al, 2002). In their immature phase of development, the metaplastic cells are most susceptible to HPV infection and possibly later to progression to CC. The metaplastic transformation zone in the ectocervix of a GM woman will repeatedly be exposed to carcinogenetic agents. For this reason, multiparity may intensify the actions of carcinogenic infectious agents (Nair and Pillai, 1992).

Our data did not include any information about the age at first intercourse, smoking or Caesarean sections also thought to be involved in the pathogenesis of CC (Bosch et al, 1992; Munoz et al,
2002). The GM women are, however, believed to be similar to the average Finnish women with respect to the most general life style factors or manner of delivery. However, in contrast to the reference population, most GM women restrain from using any kind of contraception for religious reasons. Our assumption of the low risk of STIs of the Finnish GM women proved to be true based on the low seropositivity rates to HPV and Chlamydia trachomatis, except among those who had children at an average age of less than 19 years. Both of those features are characteristic of our cohort partly for religion reason. There are also other studies with low CC risks in different religious groups as Catholic nuns, the Amish, Mormons and Jews, probably because of a smaller number of sexual partners and lowered infection risk (Schiffman et al, 1996).

Infections with oncogenic HPV types are the main causes of CC (Eluf-Neto et al, 1994). The pooled data from eight studies indicated that high parity increases the risk of SCC only in HPVpositive women (Munoz et al, 2002). There are also conflicting results. Parity may be risk factor of CC rather among HPVnegative than HPV-positive women (Brinton et al, 1989). Despite the low prevalence of HPV16- and Chlamydia trachomatis-positive women in our cohort compared to the reference population, the SIRs of CC and CIN3 were increased. This finding indicates that multiparity per se played a role in the aetiology of these diseases.

GM women who had their first child at young age were an exception to the general tendency; they had a high prevalence of HPV16 and Chlamydia trachomatis compared to other age groups and a similar or a slightly higher prevalence than in reference women of the same age. They had an increased risk of CC and CIN3, especially in premenopausal ages. This finding agrees with the results of some (Brinton et al, 1987a; Cuzick et al, 1990; Bosch et al, 1992; La Vecchia et al, 1993), but not all previous studies (Parazzini et al, 1989, 1998; Munoz et al, 1993; Mukherjee et al, 1994; Autier et al, 1996; Munoz et al, 2002).

The importance of age at first birth has been shown to disappear after inclusion parity (Parazzini et al, 1989) or the age at first marriage, education and parity (Mukherjee et al, 1994) in multiple logistic regression analysis. Theoretically, young age at first birth could be an independent risk factor for CC, because the cervix is most vulnerable at young age, when the risk of sexually transmitted diseases is most prominent. The degree of nuclear atypia increases with the duration of infection (Nair and Pillai, 1992; Schiffman et al, 1996).

Short interval between births was associated with an increased risk of CIN3 in postmenopausal GM women. The maintenance of the transformation zone on the ectocervix for a prolonged time increases its susceptibility to the external agents involved in dysplastic lesions (Autier et al, 1996). In contrast to a study from India (Mukherjee et al, 1994), where birth interval had an independent effect on risk increase of CC, our study, as in a majority of other studies (Munoz et al, 2002), failed to reveal such an association for CC.

In conclusion, although the seroprevalence of HPV16 and Chlamydia trachomatis in Finnish GM women was small, the incidence of CC and CIN3 was slightly but significantly above the national average. Multiparity seems thus to be an independent risk factor of CC also in a country with effective national programmes for an early detection and treatment of CINs. Young age at first birth also plays a significant role in the aetiology of CC and CIN3, probably in association with STIs.

\section{ACKNOWLEDGEMENTS}

This work was supported by grants from the Cancer Society of Finland, Finnish Obstetrical and Gynaecological Research Foundation and Orion Pharma Research Foundation. 


\section{REFERENCES}

Anttila A, Pukkala E, Soderman B, Kallio M, Nieminen P, Hakama M (1999) Effect of organised screening on cervical cancer incidence and mortality in Finland, 1963 -1995: recent increase in cervical cancer incidence. Int J Cancer 83: 59-65

Anttila T, Saikku P, Koskela P, Bloigu A, Dillner J, Ikaheimo I, Jellum E, Lehtinen M, Lenner P, Hakulinen T, Narvanen A, Pukkala E, Thoresen S, Youngman L, Paavonen J (2001) Serotypes of Chlamydia trachomatis and risk for development of cervical squamous cell carcinoma. JAMA 285: $47-51$

Autier PCM, Huet F, Grivegnee AR (1996) Transformation zone location and intraepithelial neoplasia of the cervix uteri. Br I Cancer 74: 488-490

Bosch FX, Munoz N, de Sanjose S, Izarzugaza I, Gili M, Viladiu P, Tormo MJ, Moreo P, Ascunce N, Gonzalez LC, Tadar L, Kaldo JM, Guerrero F, Aristizabal N, Santamaria M, Alonso de Ruiz P, Shah K (1992) Risk factors for cervical cancer in Colombia and Spain. Int J Cancer 52: 750 758

Brinton LA, Hamman RF, Huggins GR, Lehman HF, Levine RS, Mallin K, Fraumeni Jr JF (1987a) Sexual and reproductive risk factors for invasive squamous cell cervical cancer. J Natl Cancer Inst 79: 23-30

Brinton LA, Herrero R, Reeves WC, de Britton RC, Gaitan E, Tenorio F (1993) Risk factors for cervical cancer by histology. Gynecol Oncol 51: $301-306$

Brinton LA, Reeves WC, Brenes MM, Herrero R, de Britton RC, Gaitan E, Tenorio F, Garcia M, Rawls WE (1989) Parity as a risk factor for cervical cancer. Am J Epidemiol 130: 486-496

Brinton LA, Tashima KT, Lehman HF, Levine RS, Mallin K, Savitz DA, Stolley PD, Fraumeni Jr JF (1987b) Epidemiology of cervical cancer by cell type. Cancer Res 47: 1706-1711

Cuzick J, Sasieni P, Singer A (1996) Risk factors for invasive cervix cancer in young women. Eur J Cancer 32A: 836-841

Cuzick J, Singer A, De Stavola BL, Chomet J (1990) Case-control study of risk factors for cervical intraepithelial neoplasia in young women. Eur J Cancer 26: $684-690$

Dillner J, Lehtinen M, Bjorge T, Luostarinen T, Youngman L, Jellum E, Koskela P, Gislefoss RE, Hallmans G, Paavonen J, Sapp M, Schiller JT, Hakulinen T, Thoresen S, Hakama M (1997) Prospective seroepidemiologic study of human papillomavirus infection as a risk factor for invasive cervical cancer. I Natl Cancer Inst 89: 1293-1299

Eluf-Neto J, Booth M, Munoz N, Bosch FX, Meijer CJ, Walboomers JM (1994) Human papillomavirus and invasive cervical cancer in Brazil. $\mathrm{Br} J$ Cancer 69: $114-119$

Hakama M (1985) Effect of population screening for carcinoma of the uterine cervix in Finland. Maturitas 7: 3-10

Hakama M, Luostarinen T, Hallmans G, Jellum E, Koskela P, Lehtinen M, Thoresen S, Youngman L, Hakulinen T (2000) Joint effect of HPV16 with Chlamydia trachomatis and smoking on risk of cervical cancer: antagonism or misclassification (Nordic countries). Cancer Causes Control 11: 783-790

Hinkula M, Pukkala E, Kyyrönen O, Kauppila A (2001) Grand multiparity and risk of breast cancer; population-based study in Finland. Cancer Causes Control 12: $491-500$

Hinkula M, Pukkala E, Kyyrönen P, Kauppila A (2002) Grand multiparity and incidence of endometrial cancer: a population-based study in Finland. Int J Cancer 98: 912 - 915

Jones CJ, Brinton LA, Hamman RF, Stolley PD, Lehman HF, Levine RS, Mallin K (1990) Risk factors for in situ cervical cancer: results from a case-control study. Cancer Res 50: 3657-3662

Korhonen MO (1980) Epidemiological differences between adenocarcinoma and squamous cell carcinoma of the uterine cervix. Gynecol Oncol 10: $312-317$

Koskela P, Anttila T, Bjorge T, Brunsvig A, Dillner J, Hakama M, Hakulinen T, Jellum E, Lehtinen M, Lenner P, Luostarinen T, Pukkala E, Saikku P, Thoresen S, Youngman L, Paavonen J (2000) Chlamydia trachomatis infection as a risk factor for invasive cervical cancer. Int J Cancer 85: $35-39$
Kvale G, Heuch I, Nilssen S (1988) Reproductive factors and risk of cervical cancer by cell type. A prospective study. Br J Cancer 58: 820-824

La Vecchia C, Franceschi S, Decarli A, Fasoli M, Gentile A, Tognoni G (1986) Cigarette smoking and the risk of cervical neoplasia. Am J Epidemiol 123: 22-29

La Vecchia C, Negri E, Franceschi S, Parazzini F (1993) Long-term impact of reproductive factors on cancer risk. Int J Cancer 53: 215-219

Laukkanen P, Koskela P, Pukkala E, Dillner J, Läärä E, Knekt P, Lehtinen M (2003) Time trends in incidence and prevalence of human papillomavirus type 6,11 and 16 prevalence in Finland. J Gen Virol 84: 2105-2109

Lehtinen M, Dillner J, Knekt P, Luostarinen T, Aromaa A, Kirnbauer R, Koskela P, Paavonen J, Peto R, Schiller JT, Hakama M (1996) Serologically diagnosed infection with human papillomavirus type 16 and risk for subsequent development of cervical carcinoma: nested case-control study. Br Med J 312: 537-539

Mukherjee BN, Sengupta S, Chaudhuri S, Biswas LN, Maiti P (1994) A case-control study of reproductive risk factors associated with cervical cancer. Int J Cancer 59: 476-482

Munoz N, Bosch FX, de Sanjose S, Shah KV (1994) The role of HPV in the etiology of cervical cancer. Mutat Res 305: 293-301

Munoz N, Bosch FX, de Sanjose S, Vergara A, del Moral A, Munoz MT, Tafur L, Gili M, Izarzugaza I, Viladiu P, Navarro C, Alanso de Ruiz P, Anstizabal N, Santamaria M, Ordila J, Daniel RW, Guerrero E, Shah K (1993) Risk factors for cervical intraepithelial neoplasia grade III/ carcinoma in situ in Spain and Colombia. Cancer Epidemiol Biomarkers Prev 2: $423-431$

Munoz N, Franceschi S, Bosetti C, Moreno V, Herrero R, Smith JS, Shah $\mathrm{KV}$, Meijer CJ, Bosch FX, International Agency for Research on CancerMulticentric Cervical Cancer Study G (2002) Role of parity and human papillomavirus in cervical cancer: the IARC multicentric casecontrol study. Lancet 359: $1093-1101$

Nair BS, Pillai R (1992) Oncogenesis of squamous carcinoma of the uterine cervix. Int J Gynecol Pathol 11: 47-57

Parazzini F, Chatenoud L, La Vecchia C, Negri E, Franceschi S, Bolis G (1998) Determinants of risk of invasive cervical cancer in young women. Br J Cancer 77: $838-841$

Parazzini F, La Vecchia C, Negri E, Cecchetti G, Fedele L (1989) Reproductive factors and the risk of invasive and intraepithelial cervical neoplasia. Br J Cancer 59: 805-809

Parazzini F, La Vecchia C, Negri E, Fasoli M, Cecchetti G (1988) Risk factors for adenocarcinoma of the cervix: a case-control study. Br J Cancer 57: $201-204$

Parazzini F, La Vecchia C, Negri E, Fedele L, Franceschi S, Gallotta L (1992) Risk factors for cervical intraepithelial neoplasia. Cancer 69: $2276-2282$

Rotkin ID (1973) A comparison review of key epidemiological studies in cervical cancer related to current searches for transmissible agents. Cancer Res 33: $1353-1367$

Schiffman M, Brinton LA, Devesa SS, Fraumeni Jr JF (1996) Cervical cancer. Cancer Epidemiology and Prevention, 2nd edn. pp 1090-1116. Oxford: Oxford University Press

Schiffman MH, Brinton LA (1995) The epidemiology of cervical carcinogenesis. Cancer 76: $1888-1901$

Solomons B (1934) The dangerous multipara. Lancet 2: 8-11

Walboomers JM, Jacobs MV, Manos MM, Bosch FX, Kummer JA, Shah KV, Snijders PJ, Peto J, Meijer CJ, Munoz N (1999) Human papillomavirus is a necessary cause of invasive cervical cancer worldwide. J Pathol 189: $12-19$

Wallin KL, Wiklund F, Angstrom T, Bergman F, Stendahl U, Wadell G, Hallmans G, Dillner J (1999) Type-specific persistence of human papillomavirus DNA before the development of invasive cervical cancer. $N$ Engl J Med 341: 1633 - 1638

www.stat.fi. (2001) Statistics Finland, Helsinki 